\title{
Trial of new vascular clips for aortic anastomosis in a canine model
}

Shinya Masuda, MD, ${ }^{\text {a }}$ Yoshikatsu Saiki, MD, ${ }^{a}$ Satoshi Kawatsu, MD, ${ }^{a}$ Ichiro Yoshioka, MD, ${ }^{a}$ Hidenori Fujiwara, MD, ${ }^{a}$ Shunsuke Kawamoto, MD, ${ }^{a}$ Sadahiro Sai, MD, ${ }^{a}$ Atsushi Iguchi, MD, ${ }^{a}$ Naoya Sakamoto, PhD, ${ }^{\mathrm{b}}$ Toshiro Ohashi, PhD, Masaaki Sato, $\mathrm{PhD},{ }^{\mathrm{b}}$ and Koichi Tabayashi, $\mathrm{MD}^{\mathrm{a}}$

From the Department of Cardiovascular Surgery and the School of Mechanical Engineering, ${ }^{\text {b }}$ Tohoku University, Sendai, Japan.

Received for publication Dec 6, 2006; revisions received April 18, 2007; accepted for publication April 23, 2007.

Address for reprints: Shinya Masuda, MD, Department of Cardiovascular Surgery, Graduate School of Medicine, Tohoku University, 1-1 Seiryou-machi, Aoba-ku, Sendai, Japan 980-8574. (E-mail: shinyamasuda-ths@umin.ac.jp)

J Thorac Cardiovasc Surg 2007;134:723-30

$0022-5223 / \$ 32.00$

Copyright () 2007 by The American Association for Thoracic Surgery

doi:10.1016/j.jtcvs.2007.04.048
Objectives: We created a new vascular clip designed for aortic surgery. The purposes of this investigation were to examine surgical applicability in a clinically relevant aortic replacement model and to assess biomechanical strength of the clipped anastomosis and serial histologic changes in the clipped anastomotic site.

Methods: Twenty-one beagles underwent descending thoracic aortic replacement. Distal anastomosis was performed with the new clips, mimicking the cuffed anastomosis technique, and proximal anastomosis was carried out by conventional suture anastomosis. Tissue specimens of the anastomotic sites were harvested at 1 , 3,6 , and 12 months postoperatively for examination.

Results: There was no significant difference in the time required to carry out clip anastomosis (12.2 \pm 1.3 minutes) and suture anastomosis (13.7 \pm 0.9 minutes; $P=$ .38). Neither type of anastomotic site was disrupted by raising the intraluminal pressure to $280 \mathrm{~mm} \mathrm{Hg}$. Microscopically, the areas of aortic wall compressed by vascular clips appeared as hyalinized areas adjacent to surrounding collagen fibers, with no significant infiltration of inflammatory cells. Identical histologic changes were observed at the site of the sutured anastomosis. The media at the clipped anastomosis site was significantly thinner than that at the sutured anastomosis site at 1 month after the operation. However, there was no significant difference in the thickness of the media at 3 months.

Conclusions: The new vascular clips were effective in this clinically relevant model, with appropriate biomechanical strength, and the anastomotic sites underwent similar histologic changes to those observed after suture anastomosis.

$\mathrm{S}$ urgical time and intraoperative and postoperative bleeding are important factors determining the immediate outcome of surgery. ${ }^{1-4}$ Automatic staplers have quickly become accepted in gastroenterological surgery because they are technically easy to use and allow operations to be carried out more quickly. ${ }^{5}$ It was expected that new methods of carrying out vascular anastomosis quickly and with minimal bleeding would be developed on the basis of new technologies. ${ }^{6-9}$ In 1955 , Samuels ${ }^{10}$ introduced a method of vascular repair by V-shaped stainless steel clips and used them in the closure of longitudinal arteriotomy wounds and single and double anastomoses of the aorta in dogs. The clips never gained wider use in vascular surgery, however. In general, potential advantages of the vascular clips over sutures include technical ease of application, reduced anastomotic time, superior hemodynamics, and improved healing pattern of the anastomosis. Disadvantages include the potential problems in atherosclerotic vessels, lack of prospective randomized long-term follow-up, and initial costs.

In the 1980s, a new, nonpenetrating, arcuate-legged titanium vascular closure staple clip was developed by Kirsch, ${ }^{11}$ Zeebregts, ${ }^{12}$ Leppaniemi, ${ }^{13}$ and others for brain 


\author{
Abbreviations and Acronyms \\ ANOVA $=$ analysis of variance \\ $\mathrm{EM}=$ elastica-Masson \\ ePTFE = expanded polytetrafluoroethylene \\ $\mathrm{HE} \quad=$ hematoxylin-eosin
}

vascularization by the superficial temporal artery-middle cerebral artery anastomosis and has subsequently been used in experimental studies to perform different types of microvascular anastomoses. However, these clips are very small, 0.3 $\mathrm{mm}$ in width, and require the vessel wall to be everted before they can be applied. This type of vascular clip has never become widely used in aortic surgery because it is difficult to evert large vessels that have a large diameter and circumference. Hence, we designed and manufactured new vascular clips that are large enough for aortic procedures, with a 3.4-mm span between the two prongs on the ipsilateral side, yet compress only a small area of aortic wall, and which can be used to perform aortic anastomosis without everting the aortic wall.

\section{Materials and Methods}

\section{Vascular Clips and Clip Anastomosis}

The vascular clips tested in the present study were made from stainless steel (type SUS304) and were designed to minimize the aortic wall area that is compressed when they are applied (Figure 1). The clips were designed by us. The clips are approximately 5 $\mathrm{mm}$ long and have a 3.4-mm span between the two prongs on the ipsilateral side. Vascular anastomosis with our clips mimics the cuffed anastomosis technique ${ }^{14}$ (Figure 2).

\section{Operative Procedure}

Twenty-one beagles underwent replacement of the descending thoracic aorta. The beagles were treated in accordance with the Declaration of Helsinki and the Guiding Principles in the Care and Use of Animals of the American Physiologic Society. The experimental and animal care protocol was also approved by the Animal Care Committee of Tohoku University School of Medicine.

Thiopental was used for induction of anesthesia, and general anesthesia was maintained by sevoflurane inhalation. The descending thoracic aorta was exposed through the fifth intercostal space and taped at the fifth intercostal level. After we administered 200 IU/kg of heparin intravenously, a temporary shunt was established between the left common carotid artery and the right femoral artery, and the descending thoracic aorta was clamped. The descending aorta was replaced with a prosthetic graft $8 \mathrm{~mm}$ in diameter (Ube-junken Co, Tokyo, Japan). The operative time required to perform each anastomosis and the shunting time were recorded, and mean operative time per anastomosis was calculated for the last 9 operations after our procedures became steady. On average, 5 new vascular clips were used to perform the distal anastomoses, and a continuous 5-0 polypropylene suture (Ethicon, Inc, Somerville, NJ) was used for the proximal anastomoses. An expanded polytetrafluoroethylene sheet (Kouno Co, Chiba, Japan) was used to reinforce both anastomotic sites. The aorta was unclamped after the anastomosis was complete. When no further bleeding was assured, the shunt was removed. Protamine was not given. The wound was closed and the animal later regained consciousness.

\section{Assessment}

After 1 month (8 animals), 3 months (9 animals), 6 months (2 animals), and 12 months ( 2 animals), the animals were killed to allow assessment of the anastomoses. The two different types of anastomotic sites were compared with respect to operative time per anastomosis, macroscopic findings, aortographic findings, the strength of the anastomotic site, and microscopic findings.

\section{Macroscopic Findings}

We checked for the presence or absence of disruption of the native aortic tissue at the anastomotic sites and observed the retained clips.

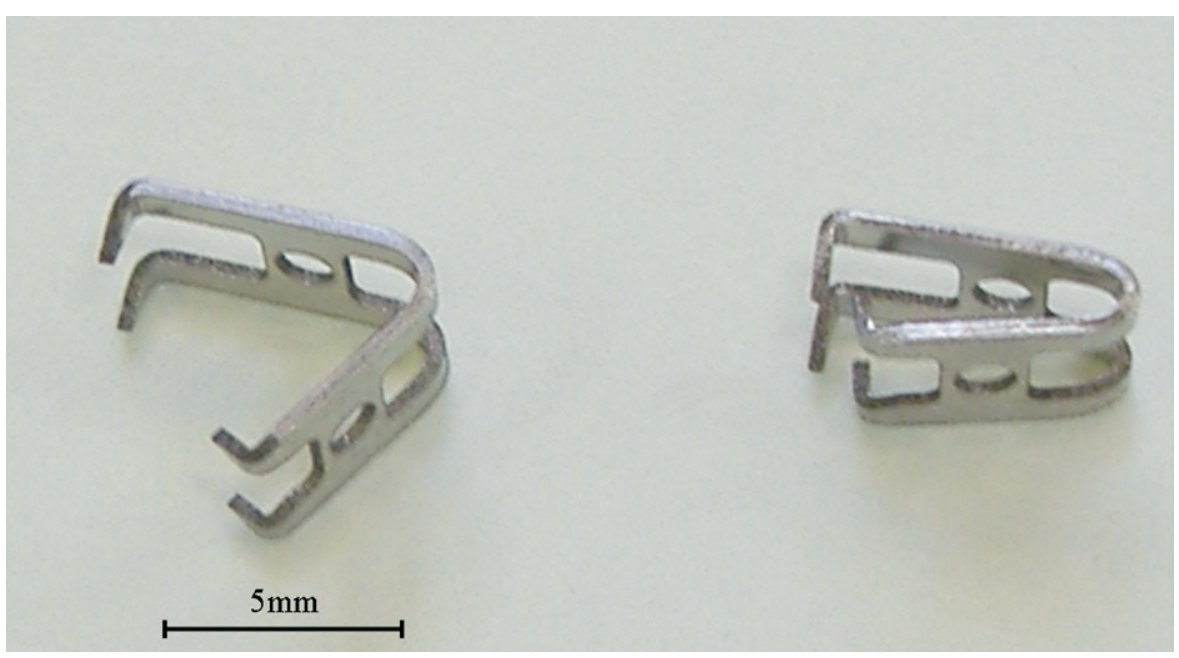

Figure 1. Vascular clips, open (left) and closed (right). The clips were manufactured from stainless steel (type SUS304) and were designed to minimize the area of aortic wall area that is compressed when they are applied. 

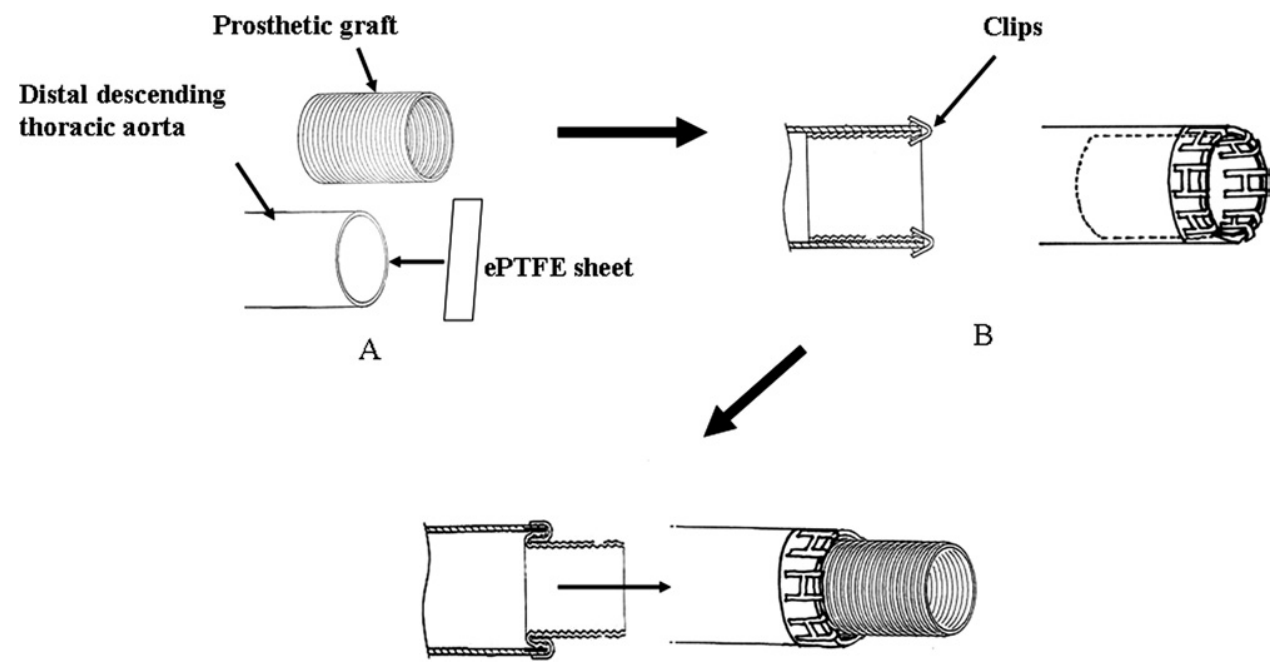

Figure 2. Vascular anastomosis using the new clips. A, An inverted prosthetic graft was inserted into the transected aorta, and an expanded polytetrafluoroethylene (ePTFE) sheet was placed around the aorta. B, The anastomotic line was aligned, and then multiple (usually 5 to 6 ) vascular clips were applied. C, The prosthetic graft was turned inside-out. Anastomosis using these clips mimics the cuffed anastomosis technique.

\section{Aortographic Analysis}

Aortography was carried out with digital subtraction angiography for live animals 1 month ( 3 animals), 3 months ( 3 animals), 6 months ( 1 animal), and 12 months ( 2 animals) after the operation.

\section{Intraluminal Pressure Test}

We defined the strength of the anastomotic site as the strength against the stresses at the anastomotic site including internal pressure, longitudinal stretch, and external oppression. As the most clinically relevant biomechanical examination, the strength of the anastomotic sites was assessed by an intraluminal pressure test 1 month and 3 months after the operation (specimens from 3 animals at each time point). The specimens used for the test were the whole descending aorta including the distal and proximal anastomotic sites and the prosthetic graft, comprising at least $3 \mathrm{~cm}$ of untreated native aorta attached to the distal and proximal anastomotic sites. After the specimens were fitted into the closed-circuit testing system using the native aorta, the interior pressure of the aorta was raised by injecting saline, and the anastomotic sites were monitored. The interior pressure was maintained above $280 \mathrm{~mm} \mathrm{Hg}$ for 2 minutes. This testing pressure and duration were chosen because in humans, blood pressure rises above $245 \mathrm{~mm} \mathrm{Hg}$ (systolic) and $160 \mathrm{~mm} \mathrm{Hg}$ (diastolic) briefly during weightlifting, ${ }^{15}$ and postoperative patients would transiently experience this degree of high blood pressure. The anastomotic site was immediately evaluated macroscopically after application of pressure.

\section{Histopathologic Analysis}

After each animal was killed, the entire descending thoracic aorta was resected and fixed in $4 \%$ formalin solution under 0 $\mathrm{mm} \mathrm{Hg}$ pressure for 24 hours. The two anastomotic sites were excised from the specimen, and the clips were gently removed. The tissue was stained with elastica-Masson (EM) and hema- toxylin-eosin (HE) for microscopic examinations to determine the mean thickness of the media at the anastomotic site and histologic changes of the aortic wall. Control sections were prepared in the same manner from tissue located $1 \mathrm{~cm}$ proximal to the anastomosis site, which corresponded to untreated native aortic wall.

Thickness of the media. The thickness of the media at the clipped anastomosis sites (Tc) and the sutured anastomosis sites (Ts) was measured. The same measurements were also carried out for control sections, which comprised tissue located $1 \mathrm{~cm}$ proximal to the anastomosis site ( $\mathrm{Tn}$ ), corresponding to untreated native aortic wall. The cross-sectional area of the media (Am) and the outer (Do) and the inner (Di) circumferences of the media were measured by EM stain. These values were used to calculate the mean thickness of the media for each section, which was defined as follows ${ }^{16}: \mathrm{Tc}$, Ts, and $\mathrm{Tn}=2 \mathrm{Am} /(\mathrm{Di}+\mathrm{Do})$. The mean values of $\mathrm{Tc} / \mathrm{Tn}$ and $\mathrm{Ts} / \mathrm{Tn}$ were used as relative measures of the thickness of the media.

Degrees of inflammatory reaction. The degrees of inflammatory reaction were assessed on the basis of the literature. ${ }^{17,18}$ Using the inflammation score, the inflammatory reaction was quantitatively classified from 0 to $3: 0=$ no cell infiltration; $1=$ sparse, focal infiltration of neutrophils, lymphocytes, and plasma cells; 2 = focal infiltration of neutrophils, plasma cells, and lymphocytes; and 3 = diffuse infiltration of neutrophils, plasma cells, and lymphocytes.

Degrees of hyaline formation. The degrees of hyalinization were assessed on the basis of the area of the hyaline formation. The longitudinal-sectional area of the aortic wall (AA) and the hyaline formation (HA) at the anastomotic site were measured for each section by HE stain. The mean values of HA/AA were used as relative measures of the area of the hyaline formation. 


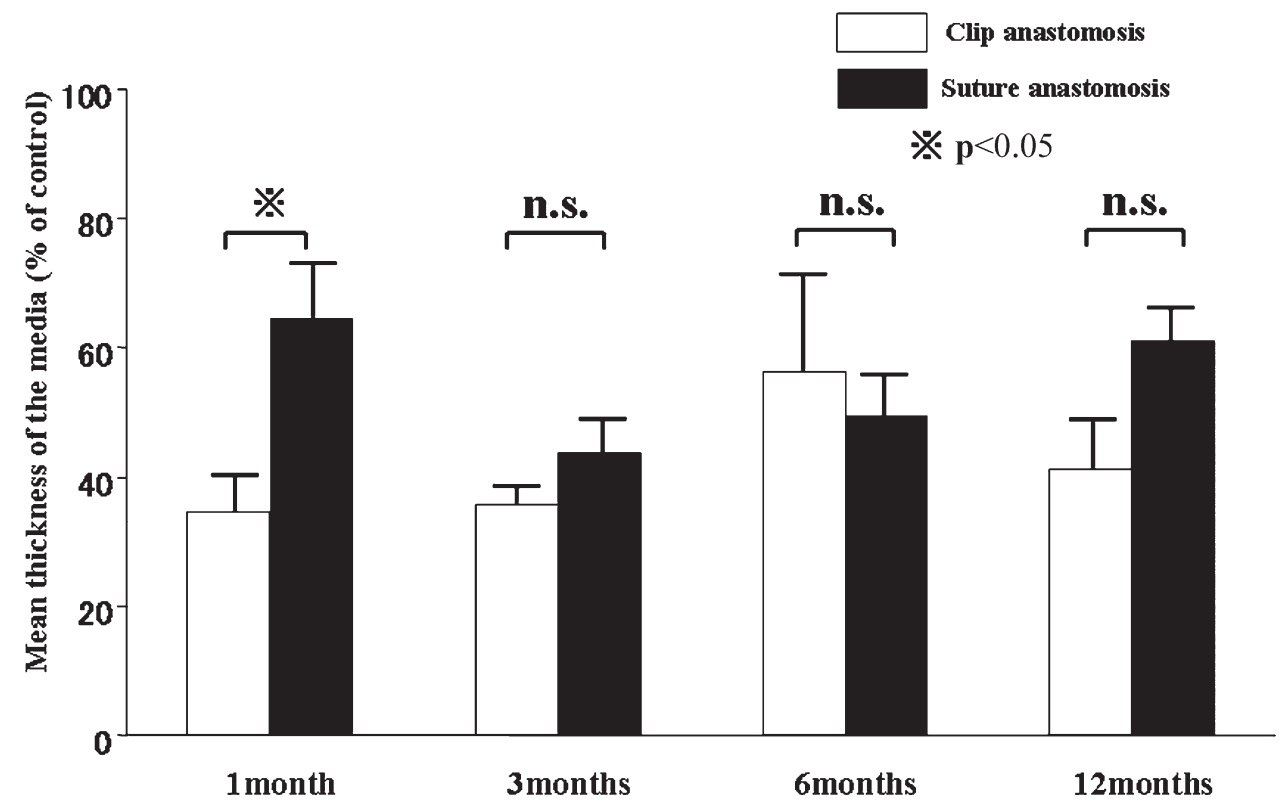

Figure 3. Thickness of the media at the anastomotic sites 1, 3, 6, and 12 months postoperatively. The thickness of the media at the anastomotic site is expressed as a ratio of normal control untreated native aortic wall. n.s., Not significant.

\section{Statistical Analysis}

Comparisons of the data between the two anastomosis types were performed by the Student unpaired $t$ test. Data for each anastomosis type for different time points were analyzed by 1-way analysis of variance (ANOVA) (SPSS.11.5 for Windows; SPSS, Chicago, IIl). Experimental results are expressed as mean \pm standard error of the mean.

\section{Results}

\section{Operative Time}

There was no significant difference in the operative time required per anastomosis between the clipped anastomosis and the sutured anastomosis (clipped anastomosis $12.2 \pm$ 1.3 minutes vs sutured anastomosis $13.7 \pm 0.9$ minutes; $P$ $=.38$ ). The average shunting time was 47 minutes. An additional clip was required to control bleeding from the anastomotic site in 2 animals, but applying it took only 5 seconds to complete. In suture anastomoses, 6 animals required additional sutures for hemostasis, and each procedure took about an additional 30 seconds to obtain hemostasis. However, we could not demonstrate the difference in additional procedures for hemostasis between the two anastomotic techniques statistically.

\section{Aortographic and Macroscopic Findings}

There were no pseudoaneurysm formation or leakage at either the proximal or distal anastomotic sites on aortography. The absence of disrupted tissue and retained clip contour was confirmed by macroscopic observation.

\section{Intraluminal Pressure Test}

The intraluminal pressure test was carried out after 1 and 3 months (using specimens from 3 animals at each time point). No anastomotic site of either type was disrupted by raising the intraluminal pressure to $280 \mathrm{~mm} \mathrm{Hg}$ for 2 minutes.

\section{Histopathologic Analysis}

Thickness of the media. The media at the clipped anastomotic site was significantly thinner than that at the sutured anastomotic site 1 month after the operation (clip anastomosis $35 \% \pm 6 \%$ of control vs sutured anastomosis $65 \% \pm$ $9 \%$ of control; $P<.05$ ), but there was no significant difference in media thickness between the two types of anastomotic sites after more than 1 month postoperatively (at 3 months: clipped anastomosis $36 \% \pm 2 \%$ of control vs sutured anastomosis $44 \% \pm 3 \%$ of control; $P=.051$; at 6 months: $56 \% \pm 16 \%$ of control vs $49 \% \pm 7 \%$ of control; $P$ $=.73$; at 12 months: $41 \% \pm 11 \%$ of control vs $61 \% \pm 5 \%$ of control; $P=.25$ ) (Figure 3).

Serial changes in the medial thickness at anastomosis within the respective anastomotic modality at the 4 different time points were analyzed by ANOVA. There was no statistically significant difference in the medial thickness throughout the follow-up.

\section{Histologic changes in the aortic wall}

THE DEGREES OF INFLAMMATORY REACTION. The inflammation score was either 0 or 1 in each type of anastomosis at 

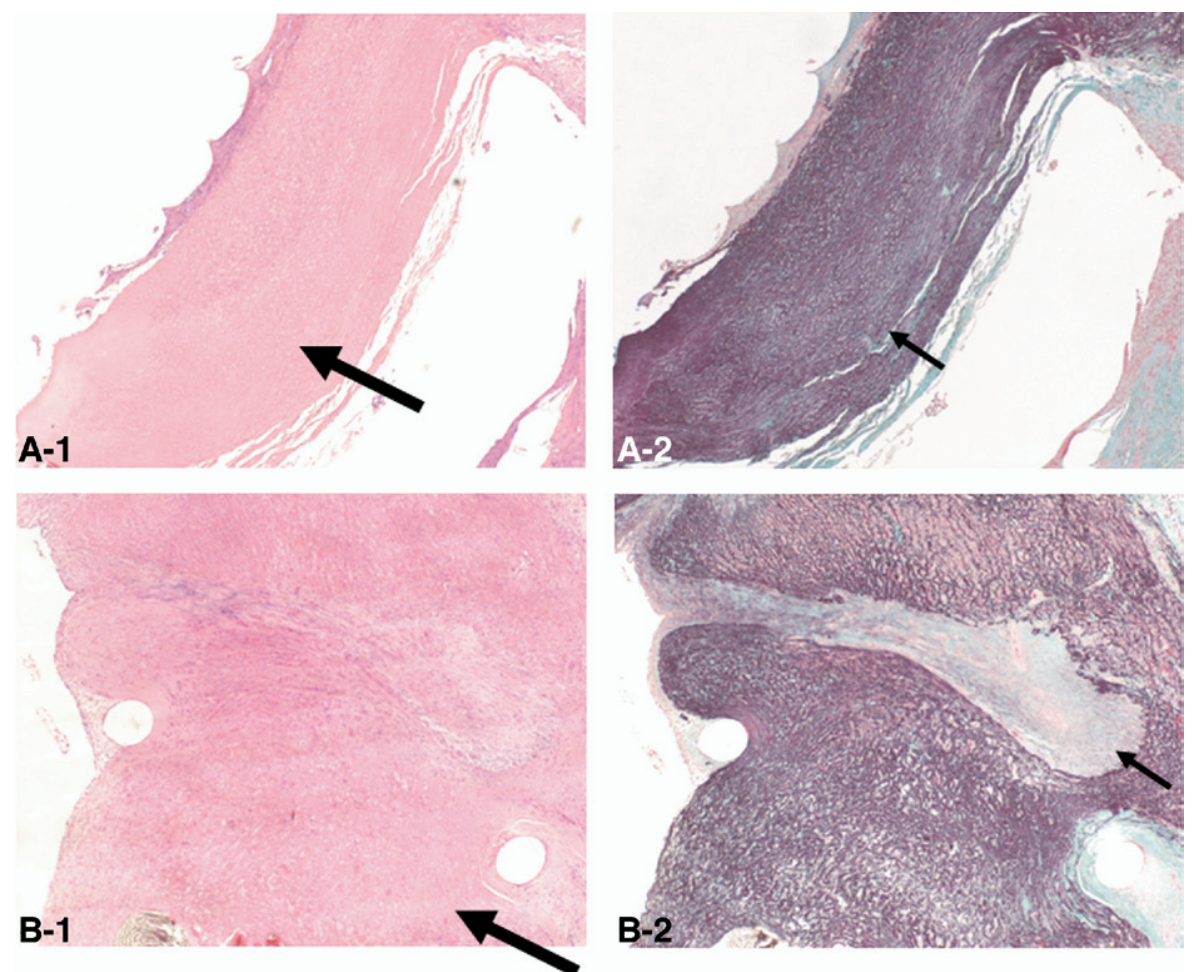

Figure 4. Histologic changes in the anastomotic sites of the aortic wall 1 month postoperatively. A, Clipped anastomotic site. The region of aortic wall that was compressed by a vascular clip appears as a hyalinized area (large arrow) adjacent to the surrounding collagen fibers (small arrow). This area was not associated with infiltration of inflammatory cells (original magnification $\times 40$ ). A-1, ElasticaMasson stain; A-2, hematoxylin-eosin stain). B, Sutured anastomotic site. Identical histologic changes were observed as for the clipped anastomotic site (original magnification $\times 40$ ). B-1, Elastica-Masson stain; B-2, hematoxylin-eosin stain. each time point during the follow-up. There was no difference between the two anastomosis types in terms of inflammatory reaction.

The Degrees OF HYALINE FORMATION. There was no difference between the two anastomosis types (at 1 month: clipped anastomosis $8.9 \% \pm 1.8 \%$ vs sutured anastomosis $13.0 \% \pm 2.8 \% ; P=.43$; at 3 months: $23.5 \% \pm 6.3 \%$ vs $19.0 \% \pm 2.9 \% ; P=.49$, at 6 months: $21.8 \% \pm 5.8 \%$ vs $28.5 \% \pm 2.6 \% ; P=.49$, at 12 months: $26.9 \% \pm 3.3 \%$ vs $21.6 \% \pm 3.3 \% ; P=.39$ ). Serial changes in the degrees of hyaline formation at anastomosis within the respective anastomotic modality at the 4 different time points were analyzed by ANOVA. There was no statistically significant difference in the degrees of hyaline formation throughout the follow-up.

Regions of aortic wall that were compressed by vascular clips appeared as hyalinized areas adjacent to the surrounding collagen fibers at 1 month postoperatively. These areas were not significantly associated with infiltration of inflammatory cells. Identical histologic changes were observed at the sutured anastomotic sites (Figure 4). Anastomotic sites of both types were histologically stable after 1 month postoperatively. After 12 months, hyalinization was obvious and marginal calcification was observed at regions of the aortic wall that were compressed by vascular clips, but infiltration of inflammatory cells was not notably seen. Identical histologic changes were observed at the sutured anastomotic sites (Figure 5). Anastomotic sites of both types were histologically stable 12 months postoperatively. We examined the development of neointimal formation. However, we did not recognize appreciable difference in the neointimal formation between the two anastomotic types.

\section{Discussion}

In this clinically relevant model of descending thoracic aortic replacement, we demonstrated that it is feasible to apply those clips to thoracic aortic surgery without excessive operative time compared with conventional suture anastomosis technique. We also confirmed that biomechanical strength of the anastomotic site created with our new clips was comparable with that of suture anastomosis when assessed with endoluminal pressure test. Furthermore, we revealed that histologic changes that the anastomotic site underwent were essentially the same as those observed after suture anastomosis in the long term.

\section{Clips}

The four-pronged shape of the newly developed clip was chosen because carrying out the anastomosis would be timeconsuming if the clip had only two prongs. If a plate shape had been used, the area of tissue compressed by the clips would have been too large. For the dogs used in this study, whose descending thoracic aorta was $10 \mathrm{~mm}$ in diameter, the clips 

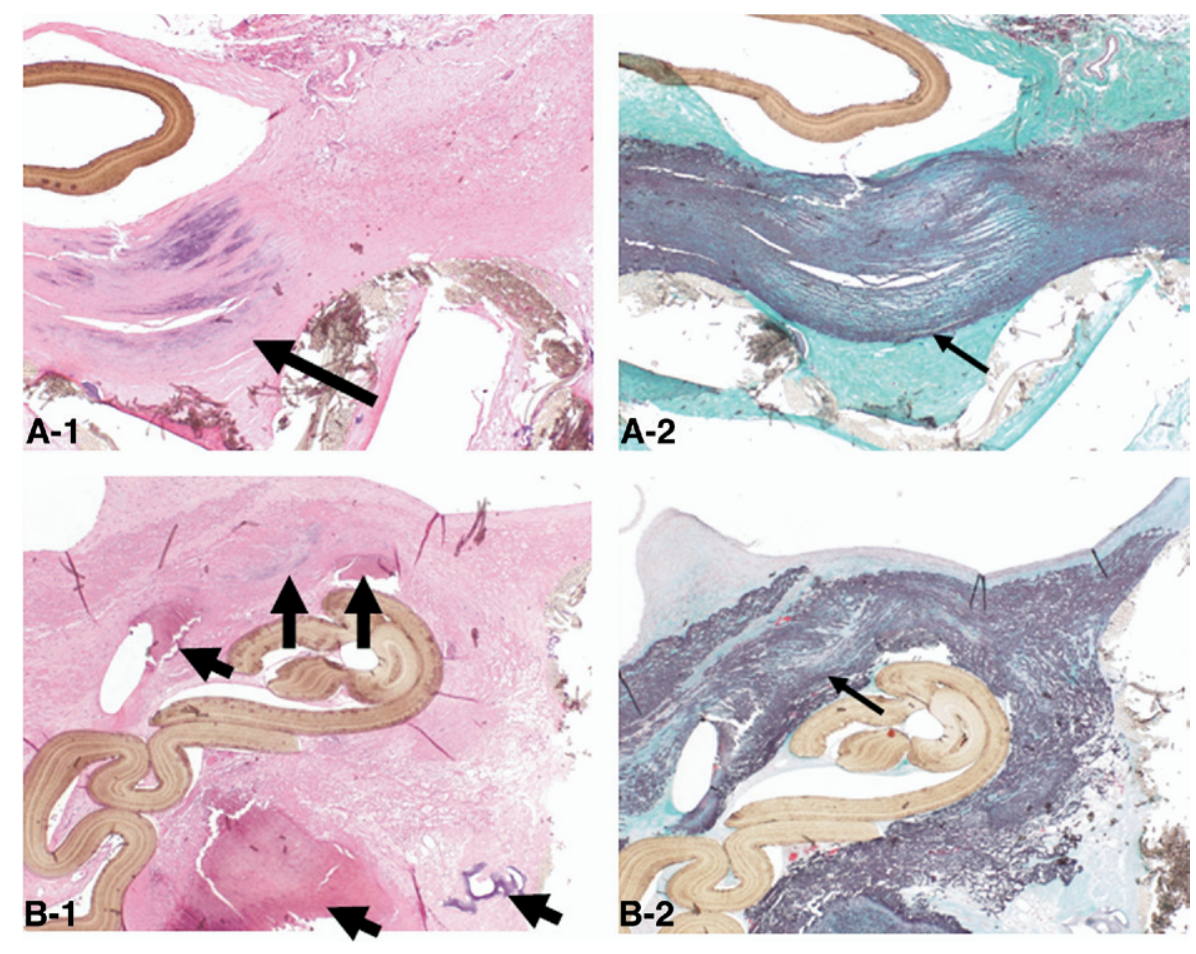

Figure 5. Histologic changes in the anastomotic sites of the aortic wall 12 months postoperatively. A, Clipped anastomotic site. The region of aortic wall that was compressed by a vascular clip appears as a hyalinized and calcified area (large arrow) adjacent to the surrounding collagen fibers (small arrow). This area was not associated with infiltration of inflammatory cells (original magnification $\times 40$ ). A-1, Elastica-Masson stain; A-2, hematoxylin-eosin stain. B, Sutured anastomotic site. Identical histologic changes were observed as for the clipped anastomotic site (original magnification $\times$ 40). B-1, Elastica-Masson stain; B-2, hematoxylin-eosin stain. Anastomotic sites of both types were histologically stable 12 months postoperatively. were $5 \mathrm{~mm}$ long and $3.4 \mathrm{~mm}$ wide. Five or six clips were needed to complete each anastomosis.

The ends of the prongs of these clips were sharp, but the clip's shape can be modified with respect to the sharpness of the prongs as well as the length and the width of the prongs. The next step will be to evaluate the shape of this clip in a mock circulation system by using anastomotic models with greater than 20-mm diameter vessels, equal to the diameter of the human aorta. The clips used in this study were manufactured from stainless steel (type SUS304). This material is known to be durable and not subject to corrosion fatigue. ${ }^{19}$ However, there is room for us to assess other materials, such as titanium, which has been widely used in the human body.

\section{Clip Anastomosis}

The clip anastomosis technique used in this study mimics the cuffed anastomosis method that is widely performed clinically. Although this clip technique can be performed at the proximal site as well, we used the clip on the distal end because we had an image on our mind to apply clip anastomosis practically in a deep surgical field. In our study, the additional time required to achieve complete hemostasis was not measured precisely, because we believed that the incidence of bleeding from the suture line might also depend on the performer's skill rather than the methodologic difference. As recorded facts in our notes, an additional clip was required to control bleeding in 2 animals; this took only 5 seconds to complete. In suture anastomoses, 6 animals required additional sutures for hemostasis. Each procedure took about an additional 30 seconds to obtain hemostasis. Although we could not demonstrate the difference in additional procedures for hemostasis between the two anastomotic techniques statistically, we had a good sense that the risk of bleeding from the suture line was less with the clip.

When a customized long, flexible application tool, together with a customized removal tool and forceps, are developed, the clips and tools will permit the minithoracotomy surgical approach (in which endoscopic and videoscopic vascular procedures are used) to be used for aortic surgery in operative fields that have hitherto been inaccessible. These devices will also reduce the operative time required to accomplish anastomosis relative to conventional suture anastomosis. In fact, our clip anastomosis technique was efficacious in a deep surgical field with intentionally limited access area when we performed some experiments as a pilot study. In short, we could carry out clip anastomosis in 2 animals setting up a deep surgical field using a cylinder $15 \mathrm{~cm}$ in height and $7.5 \mathrm{~cm}$ in diameter. It is conjectured that the minithoracotomy surgical approach will be the situation in which our clips play an indispensable role.

With regard to durability of clip anastomosis, no anastomotic sites of either type were disrupted by raising the intraluminal pressure to $280 \mathrm{~mm} \mathrm{Hg}$ for 2 minutes. This finding suggests that the clipped anastomotic site bears 
equivalent strength to the suture anastomotic site against radial force. However, other modes of biomechanical testing including longitudinal stretch test and distortion test will be required, especially after 3 months' interval before its introduction to clinical arena.

\section{Consideration of Histopathologic Consequences}

The important factors affecting anastomotic strength have been identified by many studies. ${ }^{20-28}$ Tensile strength borne by a prosthetic vascular graft, suture material, and the aortic wall are the three components related to anastomotic strength. As far as aortic wall strength is concerned, medial elastic fibers ${ }^{29,30}$ and neoadventitia ${ }^{20-23}$ are the two determining factors. When there is not an appreciable difference in the adventitial area between the two modes of anastomosis, the medial thickness would be a target of interest.

The media at the clipped anastomosis sites was significantly thinner than that at the sutured anastomosis sites 1 month postoperatively, but there was no significant difference between the two types of anastomosis sites 3 months postoperatively, since the medial thickness at the suture anastomosis decreased between 1 month and 3 months postoperatively. However, that change in the medial thickness per se did not reach the statistical significance analyzed by 1-way ANOVA test. The aortic specimens from 12months' follow-up were almost identical to the ones from 1-month follow-up, which may implicate that medium-term stability of the clipped aortic anastomosis.

One of the possible concerns on the anastomotic sites created with vascular clips is blockage of the vasa vasorum to the aortic wall by chronic compression of the localized aortic wall. However, this was not the major drawback of the clipped anastomosis using our newly created clips as evidenced in the results of serial histopathologic changes that the clipped anastomotic sites underwent. Hyalinization was, in fact, present at the clipped anastomotic sites, but the degree of hyalinization did not exceed that in suture anastomosis. After 1 month postoperatively, the anastomotic site underwent no new reactive changes such as inflammatory reaction (assessed 3, 6, and 12 months postoperatively), and there were no marked histologic changes during the mid-term follow-up. In fact, it may not be conclusive that an absence of inflammatory reaction is beneficial. However, it may be said that an absence of inflammatory infiltrates may not cause further exacerbating conditions such as on the tissue.

We consider that the tissue at the anastomotic site had completely healed by 3 months postoperatively and that this condition was maintained thereafter.

\section{Conclusions}

We reached the following conclusions: (1) The new vascular clips were suitable for use in this clinically relevant aortic replacement model; (2) the time required to carry out vascular anastomosis using the new vascular clips was the same as that for suture anastomosis; (3) clipped anastomoses have appropriate biomechanical strength against high internal pressure; and (4) histologic changes observed at anastomotic sites where multiple vascular clips had been placed were essentially the same as those observed after suture anastomosis.

We express our appreciation to Masaki Ooi, Takatomo Ushiyama, and Junichi Yamazaki for their technical support with the intraluminal pressure tests. We also thank Dr Takuya Moriya for assistance with histologic analysis and Dr Shoko Komatsu for her advice on statistical analysis.

\section{References}

1. Griepp RB, Stinson EB, Hollingsworth JF, Buehler D. Prosthetic replacement of the aortic arch. J Thorac Cardiovasc Surg. 1975;70: 1051-63.

2. Svensson LG. Rationale and technique for replacement of the ascending aorta, arch, and distal aorta using a modified elephant trunk procedure. J Cardiovasc Surg. 1992;7:301-12.

3. Sakamoto T, Yoshida T, Sugano T, Kudoh A, Suzuki A. Simplified technique for hemi-arch replacement during open distal anastomosis: the Calla method. Ann Thorac Surg. 1996;61:1021-3.

4. Tabayashi K, Ohmi M, Togo T, Murata M, Yokoyama H, Akimoto H, et al. Aortic arch aneurysm repair using selective cerebral perfusion. Ann Thorac Surg. 1994;57:1305-10.

5. Hori S, Ochiai T, Gunji Y, Hayashi H, Suzuki T. A prospective randomized trial of hand-sutured versus mechanically stapled anastomoses for gastroduodenostomy after distal gastrectomy. Gastric Cancer. 2004;7:24-30.

6. Gundry SR, Black K, Izutani H. Sutureless coronary artery bypass with biologic glued anastomoses: preliminary in vivo and in vitro results. J Thorac Cardiovasc Surg. 2000;120:473-7.

7. Yoshida K, Ohtake H, Kimura K, Watanabe G. Experimental study of aortic anastomosis using a circular stapling device in the porcine model. Eur J Vasc Endovasc Surg. 2006;31:575-80.

8. Elkouri S, Noel AA, Gloviczki P, Karnicki K, Douglas CJ, Phelps RR, et al. Stapled aortic anastomoses: a minimally invasive, feasible alternative to videoscopic aortic suturing? Vasc Endovasc Surg. 2004;38: 321-30.

9. Suyker WJL, Buijsrogge MP, Suyker PTW, Verlaan CWJ, Borst C, Grundeman PF. Stapled coronary anastomosis with minimal intraluminal artifact: the $S^{2}$ anastomotic system in the off-pump porcine model. J Thorac Cardiovasc Surg. 2004;127:498-503.

10. Samuels PB. Method of blood vessel anastomosis by means of metal clips. Arch Surg. 1955;70:29-38.

11. Kirsch WM, Zhu YH, Hardesty RA, Petti G, Furnas D. Nonpenetrating clips successfully replacing sutures in base of skull surgery. Skull Base Surg. 1993;3:171-81.

12. Zeebregts CJ, Kirsch WM, van den Dungen JJ, Zhu YH, van Schilfgaarde R. Five years' world experience with nonpenetrating clips for vascular anastomoses. Am J Surg. 2004;187:751-60.

13. Leppaniemi A, Wherry D, Pikoulis E, Hufnagel H, Waasdorp C, Fishback N, et al. Arterial and venous repair with vascular clips: comparison with suture closure. J Vasc Surg. 1997;26:24-8.

14. Oda K, Akimoto H, Hata M, Akasaka J, Yamaya K, Iguchi A, et al. Use of cuffed anastomosis in total aortic arch replacement. Ann Thorac Surg. 2003;76:952-3.

15. McArdle WD, Katch FI, Katch VL. Blood pressure and exercise. In: Exercise physiology, 4th ed. Baltimore: Williams \& Wilkins; 1996. p. 276-83.

16. Nio M, Takahashi T, Ohi R. A morphological and morphometric study of the intrahepatic portal veins in patients with biliary atresia and portal hypertension. Jpn J Pediatr Surg. 1998;20:133-40. 
17. Sakuma K, Iguchi A, Ikada K, Tabayashi K. Closure of the pericardium using synthetic bioabsorbable polymers. Ann Thorac Surg. 2005; 80:1835-40.

18. Lu JH, Chang Y, Sung HW, Chiu YT, Yang PC, Hwang BH. Heparinization on pericardial substitutes can reduce adhesion and epicardial inflammation in the dog. J Thorac Cardiovasc Surg. 1998;115: 1111-20.

19. Bever MB. Encyclopedia of materials science and engineering. In: Iron-based biomechanical materials. Vol. 3. Oxford: Pergamon Press; 1986. p. $2430-8$.

20. Miyata T, Takagi A, Sato O, Takayama Y, Koyama H, Kimura H, et al. The influence of vascular graft structure on the formation of anastomotic aneurysm. Jpn J Artif Organs. 1995;24:1107-13.

21. Kumamoto Y. Experimental study of tensile strength in arterioprosthetic anastomosis. Nippon Geka Gakkai Zasshi. 1984;85:102-9.

22. Ashizawa K. An experimental study of the strength in arterial prosthetic anastomoses: relationship between anastomotic tensile strength and its organization. Nippon Geka Gakkai Zasshi. 1991; 92:874-84.
23. Hohf RP. Tensile strength of the arterial-prosthesis anastomosis during healing. Ann Surg. 1962;156:805-10.

24. Moore WS, Hall AD. Late suture failure in the pathogenesis of anastomotic false aneurysms. Ann Surg. 1970;172:1064-8.

25. Richardson JV, McDowell HA Jr. Anastomotic aneurysms following arterial grafting: 10-year experience. Ann Surg. 1976;184:179-82.

26. Warren R, McCombs HL. Morphologic studies on plastic arterial prostheses in humans. Ann Surg. 1965;161:73-82.

27. Kumada J, Motohashi H, Takemiya S, Matsumoto A, Wada T, Matsushita K. Pathology studies on the anastomotic aneurysm. Jpn J Artif Organs. 1972;1:128-32.

28. Moore WS, Hall AD, Allen RE. Tensile strength of the arterialprosthesis anastomoses. J Surg Res. 1972;13:209-14.

29. Matsumoto A, Kumada J, Kondo H, Sato J, Wada T. Thoracic aortic aneurysm. Kyobu Geka. 1975;28:87-93.

30. Carr-White GS, Afoke A, Birks EJ, Hughes S, O'Halloran A, Glennen $\mathrm{S}$, et al. Aortic root characteristics of human pulmonary autografts. Circulation. 2000;102(Suppl 3):III15-21.

\section{Notice of Retraction}

This article has been retracted at the request of the editor due to its close similarity to a previously published article: Drug-eluting stents versus coronary artery bypass grafting in patients with diabetes mellitus. Ann Thorac Surg 2006;82:1692-7. On further investigation the editor was also concerned by some data irregularities. 